\title{
Decavanadate Binding to a High Affinity Site near the Myosin Catalytic Centre Inhibits F-Actin-Stimulated Myosin ATPase Activity ${ }^{\dagger}$
}

\author{
Teresa Tiago, ${ }^{*, \ldots}$ Manuel Aureliano, ${ }^{\ddagger}$ and Carlos Gutiérrez-Merino ${ }^{\S}$ \\ Departamento de Química e Bioquímica, Faculdade de Ciências e Tecnologia, Universidade do Algarve, 8000 Faro, Portugal, \\ and Departamento de Bioquímica y Biología Molecular, Facultad de Ciencias, Universidad de Extremadura, \\ 06071 Badajoz, Spain
}

Received January 12, 2004; Revised Manuscript Received March 6, 2004

\begin{abstract}
Decameric vanadate $\left(\mathrm{V}_{10}\right)$ inhibits the actin-stimulated myosin ATPase activity, noncompetitively with actin or with ATP upon interaction with a high-affinity binding site $\left(K_{\mathrm{i}}=0.27 \pm 0.05 \mu \mathrm{M}\right)$ in myosin subfragment-1 (S1). The binding of $\mathrm{V}_{10}$ to $\mathrm{S} 1$ can be monitored from titration with $\mathrm{V}_{10}$ of the fluorescence of S1 labeled at Cys-707 and Cys-697 with $N$-iodo-acetyl- $N{ }^{\prime}$-(5-sulfo-1-naphthyl)ethylenediamine (IAEDANS) or 5-(iodoacetamido) fluorescein, which showed the presence of only one $\mathrm{V}_{10}$ binding site per monomer with a dissociation constant of $0.16-0.7 \mu \mathrm{M}$, indicating that $\mathrm{S} 1$ labeling with these dyes produced only a small distortion of the $\mathrm{V}_{10}$ binding site. The large quenching of AEDANSlabeled $\mathrm{S} 1$ fluorescence produced by $\mathrm{V}_{10}$ indicated that the $\mathrm{V}_{10}$ binding site is close to Cys-697 and 707 . Fluorescence studies demonstrated the following: (i) the binding of $\mathrm{V}_{10}$ to $\mathrm{S} 1$ is not competitive either with actin or with $\mathrm{ADP} \cdot \mathrm{V}_{1}$ or $\mathrm{ADP} \cdot \mathrm{AlF}_{4}$; (ii) the affinity of $\mathrm{V}_{10}$ for the complex $\mathrm{S} 1 / \mathrm{ADP} \cdot \mathrm{V}_{1}$ and $\mathrm{S} 1 /$ $\mathrm{ADP} \cdot \mathrm{AlF}_{4}$ is 2- and 3-fold lower than for $\mathrm{S} 1$; and (iii) it is competitive with the S1 "back door" ligand $\mathrm{P}^{1} \mathrm{P}^{5}$-diadenosine pentaphosphate. A local conformational change in $\mathrm{S} 1$ upon binding of $\mathrm{V}_{10}$ is supported by (i) a decrease of the efficiency of fluorescence energy transfer between eosin-labeled F-actin and fluorescein-labeled S1, and (ii) slower reassociation between S1 and F-actin after ATP hydrolysis. The results are consistent with binding of $\mathrm{V}_{10}$ to the Walker A motif of ABC ATPases, which in S1 corresponds to conserved regions of the P-loop which form part of the phosphate tube.
\end{abstract}

Although vanadium is one of the important transition elements in biology (1), its physiological role is still a matter of debate. At neutral $\mathrm{pH}$ and through the range of concentrations most frequently employed in biochemical studies, the predominant vanadate species are the monomer $\left(\mathrm{H}_{2} \mathrm{VO}_{4}{ }^{-}\right)$, dimer $\left(\mathrm{H}_{3} \mathrm{~V}_{2} \mathrm{O}_{7}^{-}\right)$, and cyclic tetramer $\left(\mathrm{V}_{4} \mathrm{O}_{12}{ }^{4-}\right)(2,3)$. Other oligomers can also be formed; probably the most important of them in biochemical terms is decameric vanadate $\left(\mathrm{V}_{10} \mathrm{O}_{28}{ }^{6-}\right) .{ }^{1}$ Despite the low concentrations of vanadium

This work was supported by the Ph.D. Grant SFRH/BD/2924/2000 from Portuguese Foundation for Science and Technology (FCT) and by the POCTI program financed through FEDER for the research project 38191/QUI/2001.

* Corresponding author. E-mail: ttiago@ualg.pt.

$\doteqdot$ Universidade do Algarve.

\& Universidad de Extremadura.

${ }^{1}$ Abbreviations: ADP, adenosine 5'-diphosphate; $\mathrm{AP}_{5} \mathrm{~A}, \mathrm{P}^{1} \mathrm{P}^{5}$ diadenosine pentaphosphate; ATP, adenosine 5'-triphosphate; DTT, dithiothreitol; EDTA, ethylenediaminetetraacetic acid; eosin, eosin-5iodoacetamide; F-actin, polymerized form of monomeric actin; FDNB, 2,4-dinitro-1-fluorobenzene; FRET, fluorescence resonance energy transfer; Hepes, 4-(2-hydroxyethyl)-1-piperazine ethane sulfonic acid; IAEDANS, $N$-iodoacetyl- $N$-(5-sulfo-1-naphthyl) ethylenediamine; IAF, 5-(iodoacetamido) fluorescein; IU, amount of enzyme that release 1 $\mu$ mole of product per minute; $\mathrm{M}$, myosin; Mes, $2-(N$-morpholino $)$ ethanesulfonic acid; mant-AMPPNP, 2'-(or-3')- $O$-( $N$-methylanthraniloyl)- $\beta: \gamma$-imidoadenosine $5^{\prime}$-triphosphate; $\mathrm{P}_{\mathrm{i}}$, inorganic phosphate; $\mathrm{S} 1$, myosin subfragment 1; SDS, sodium dodecyl sulfate; SH1, most reactive thiol (Cys 707) on myosin; SH2, Cys 697; Tris- $\mathrm{HCl}$, tris(hydroxymethyl)aminomethane hydrochloride; TNBS, 2,4,6-trinitrobenzenesulfonic acid; $\mathrm{UV}$, ultra violet; $\mathrm{V}_{1}$, orthovanadate; $\mathrm{V}_{10}$, decameric vanadate species. found in cells and tissues of higher organisms, vanadate oligomers once administered or formed at special cell sites may become inaccessible to hydrolysis and reduction due to their stabilization upon binding to target ligands (4). Indeed, recent work from our laboratory $(5,6)$ demonstrated that an acute exposure to decameric vanadate species, but not exposure to monomeric vanadate, induced oxidative stress and lipid peroxidation, pointing out the importance of taking into account different vanadate oligomers in the evaluation of vanadium toxicity.

The ability of vanadate to inhibit enzymes is linked to its physical and chemical properties as well as to its flexible coordination chemistry. Vanadate monomer can act as a ground state or transition state analogue of inorganic phosphate, which has made this ion a valuable tool for studying enzyme-catalyzed phosphotransfer and phosphohydrolase reactions (7). This is particular relevant for myosin (M), the major ATPase of muscle, that is strongly inhibited by vanadate. The head segment of myosin, called subfragment 1 (S1), contains the binding sites for ATP and actin, and is responsible for the ATPase activity during the process of muscle contraction (8). The binding of ATP reduces the affinity of myosin for actin, and the subsequent hydrolysis of ATP results in a ternary complex between myosin, ADP. and inorganic phosphate $\left(\mathrm{P}_{\mathrm{i}}\right)$. The rate-limiting step of the ATP hydrolysis is the release of $\mathrm{P}_{\mathrm{i}}$ from myosin, which is accelerated by the rebinding of actin (9). Vanadate inhibits myosin ATPase activity by forming, in the absence of actin, 
a very stable complex with $\mathrm{MgADP}$ that mimics either the transition state of hydrolysis or the ADP $\cdot \mathrm{P}_{\mathrm{i}}$ intermediate state (10). In the presence of actin, the rate of vanadate release increases by $10^{5}$ compared to that of $\mathrm{M} \cdot \mathrm{ADP} \cdot \mathrm{V}_{1}$ alone $(5 \times$ $\left.10^{-6} \mathrm{~s}^{-1}\right)(11)$. Although the actin-stimulated myosin ATPase activity has been described to be about $90 \%$ inhibited by $\mathrm{ADP} \cdot \mathrm{V}_{1}$ (12), it was suggested that this inhibition could be due in part to the presence of polymeric vanadate ions, because high vanadate concentrations $(>900 \mu \mathrm{M})$ are needed (13). In fact, it has been suggested that tetrameric vanadate $\left(\mathrm{V}_{4}\right)$ interacts with myosin, being responsible for the vanadate-induced photolytic cleavage of myosin subfragment 1 $(14,15)$. More recently, Yount et al. (16) have proposed that in the presence of excess $\mathrm{V}_{\mathrm{i}}$ (a mixture of monomeric and polymeric vanadate ions), $\mathrm{V}_{\mathrm{i}}$ could enter the active site via the "back door" to form the more stable $\mathrm{MgADP} \cdot \mathrm{V}_{\mathrm{i}} \cdot$ myosin complex to relax the fibers.

Besides $\mathrm{V}_{4}$, there are indications that also vanadate decamer $\left(\mathrm{V}_{10}\right)$ may interact with myosin (17), although little is known about its putative binding sites and functional relevance. More recently, fluorescent quenching studies have provided evidence for decavanadate high-affinity binding sites in myosin (18). We now show that the actin-stimulated myosin ATPase activity is indeed strongly inhibited by $\mathrm{V}_{10}$ and that this inhibition is due to the binding of this covalently closed polyanionic species of ellipsoidal-like shape $(4,19)$ to a specific high-affinity site in the myosin headgroup.

In a previous study using the intrinsic fluorescence of myosin to monitor decavanadate-myosin interaction (18), it was suggested that myosin has binding site(s) for decavanadate with an overall dissociation constant in the micromolar range at high ionic strength $(0.3 \mathrm{M} \mathrm{KCl})$. We have named them "high affinity" site(s) because in the titration of the intrinsic fluorescence of myosin with up to $1 \mathrm{mM}$ decavanadate showed a biphasic pattern with further quenching in the sub-millimolar range (Tiago, T., Aureliano, M., and Gutiérrez-Merino, C., unpublished results). However, the limited solubility of overall myosin molecules precluded extending this study to lower ionic strength. In addition, because of the scattered distribution of Trp in the myosin 3D structure, and the occurrence of photon energy migration between them in the protein structure, the location of the putative interactions site(s) between decavanadate and myosin remained to be clarified.

Because myosin subfragment 1 (S1) labeled with fluorescent dyes at Cys-707 and Cys-697 have been widely used to monitor interactions of different modulators of the actinstimulated myosin ATPase activity (see for example refs 2023), we explored whether these labeled S1 can be used to gain a deeper knowledge of decavanadate-myosin interactions. These cysteines, termed SH1, and SH2, are the most commonly modified residues in myosin, being highly reactive with a variety of sulfhydryl directed compounds (24). Although they do not appear to be directly involved in ATP hydrolysis, they are located at a key position in the path of intersite signal transmission $(21,24,25)$, which makes them suitable reporter groups to monitor the functional events on the myosin head. In the present study, we report kinetic and fluorimetric studies on the effects of decavanadate on the actin-stimulated S1 ATPase activity and fluorescence of S1 labeled with IAEDANS and IAF at Cys-707 and Cys-697. In addition, the possibility of modulation of the F-actin/S1 complex by decavanadate has been studied by light scattering and FRET measurements as well as the effect of decavanadate on actin polymerization/depolymerization by light scattering measurements and fluorescence depolarization of eosin-labeled actin.

\section{MATERIALS AND METHODS}

Reagents. Chemicals used to prepare buffers were reagent grade. Ammonium metavanadate was purchased from Riedelde-Häen (Germany). DTT, FDNB, ATP, ADP, AP 5 A, $\mathrm{NADH}$, phosphoenolpyruvate, trypsin, and $\alpha$-chymotrypsin were supplied by Sigma Chemical Co (St. Louis, MO). Pyruvate kinase and lactate dehydrogenase were purchased from Roche Molecular Biochemicals (Mannheim, Germany). $N$-Iodo-acetyl- $N$ '-(5-sulfo-1-naphthyl)ethylenediamine (IAEDANS), 5-(iodoacetamido) fluorescein (IAF), eosin-5-iodoacetamide, and mant-AMPPNP were supplied by Molecular Probes (Eugene, OR).

Proteins. Myosin was prepared from leg and dorsal white rabbit skeletal muscle, as previously described by Pires et al. (26). Subfragment 1 was prepared by chymotryptic digestion of myosin according to Margossian and Lowey (27). F-Actin was prepared from acetone powder of rabbit skeletal muscle as described by Pardee and Spudich (28). Protein concentrations were determined spectrophotometrically by using extinction coefficients of $E_{280}^{1 \%}=5.7 \mathrm{~cm}^{-1}$ for myosin, $E_{280}^{1 \%}=7.5 \mathrm{~cm}^{-1}$ for $\mathrm{S} 1$ and $E_{290}^{1 \%}=11.5 \mathrm{~cm}^{-1}$ for actin. The molecular masses used were 500, 115, and 42 $\mathrm{kDa}$ for myosin, $\mathrm{S} 1$, and actin, respectively.

Vanadate Solutions. Stock solutions of decavanadate were prepared in a manner that maximized the proportion of vanadate that was present as the decamer, by adjusting the $\mathrm{pH}$ of the metavanadate stock solutions $\left(50 \mathrm{mM} \mathrm{NH}_{4} \mathrm{VO}_{3}\right.$, $\mathrm{pH} 6.0-7.0$ ) to $\mathrm{pH}$ between 3 and 5 (29). It has been shown by NMR spectroscopy that a decavanadate stock solution contains exclusively decameric vanadate species (30). On the other hand, only for metavanadate concentrations lower than $200 \mu \mathrm{M}$, orthovanadate species are exclusively present $(30,31)$. In contrast to the labile oxovanadates, which interconvert on the time scale of milliseconds to seconds, decameric vanadate has a very slow dissociation kinetics upon dilution (32). The kinetics of dissociation of decameric species in the experimental conditions used in this study (25 ${ }^{\circ} \mathrm{C}, 20 \mathrm{mM}$ Hepes, $\mathrm{pH}$ 7.0) assessed by measurements of the absorption at $400 \mathrm{~nm}$ (an absorption band that is characteristic of decameric vanadate) is confirmed as a firstorder kinetic process with a half-life of $158 \mathrm{~min}$ (measured with $50 \mu \mathrm{M}$ total vanadium concentration). Therefore, this oxoanion remains stable during the period used in the experiments. Metavanadate or decavanadate solutions were added to the assays from the concentrated form or from a 10 -fold dilution of the stock solutions. The $\mathrm{pH}$ changes of the assay medium during titration with decavanadate or metavanadate solutions were always less than $0.05 \mathrm{pH}$ units.

Kinetic Studies. Steady-state assays of the $\mathrm{Mg}^{2+}$-ATPase and the actin-activated S1 ATPase were measured spectrophotometrically at $25^{\circ} \mathrm{C}$ using the coupled enzyme pyruvate kinase/lactate dehydrogenase assay (33) with the following reaction mixture: $20 \mathrm{mM}$ Hepes ( $\mathrm{pH} 7.0), 2.5 \mathrm{mM} \mathrm{MgCl}_{2}$, 0.1-2 mM ATP, $0.42 \mathrm{mM}$ phosphoenolpyruvate, $0.375 \mathrm{mM}$ NADH, 18 IU lactate dehydrogenase, and 18 IU pyruvate 
kinase. The detection system was not affected by the range of decavanadate concentrations used in this study $(0-100$ $\mu \mathrm{M}$ total vanadate concentration), as was confirmed by a rapid decrease in absorbance at $340 \mathrm{~nm}$ upon addition of 40 $\mu \mathrm{M}$ ADP after the assay.

Covalent Modification of Proteins. Myosin S1 (5-6 mg/ $\mathrm{mL}$ ) was labeled at SH1 (Cys-707) with IAEDANS or IAF as previously described $(20,24)$. Prior to labeling, S1 was dialyzed against $60 \mathrm{mM} \mathrm{KCl}, 25 \mathrm{mM}$ Hepes, $\mathrm{pH}$ 7.5. The dialyzed sample was then incubated on ice for $1 \mathrm{~h}$ in the dark with a 20 -fold molar excess of IAEDANS (dissolved in the same buffer) or with a 5-fold molar excess of IAF (dissolved in buffer at $\mathrm{pH}$ 9.0). The reaction was stopped by adding an excess of DTT, and unreacted probe was subsequently removed on a PD-10 column (Pharmacia). These labeled S1 samples are named as S1(AEDANS, SH2) and S1(AF, SH2), respectively. Myosin S1 (5-6 mg/mL) was also labeled at SH2 (Cys-697) with IAEDANS or IAF as previously described $(20,24)$. To avoid the labeling of Cys-707, this residue was reversibly blocked by reacting S1 with a 2-fold molar excess of FDNB at $4{ }^{\circ} \mathrm{C}$ for $30 \mathrm{~min}$ in the presence of $1 \mathrm{mM} \mathrm{MgCl}, 1 \mathrm{mM}$ ADP, $60 \mathrm{mM} \mathrm{KCl}$, and $25 \mathrm{mM}$ Hepes, $\mathrm{pH}$ 8.0. FDNB-protected $\mathrm{S} 1$ was subsequently incubated at $4{ }^{\circ} \mathrm{C}$ for $1 \mathrm{~h}$ in the dark in the presence of $5 \mathrm{mM} \mathrm{MgCl} 2$ and $5 \mathrm{mM}$ ADP with a 8 -fold molar excess of IAEDANS or with a 2-fold molar excess of IAF. The reaction was stopped by the addition of $10 \mathrm{mM}$ DTT and the protective dinitrobenzene group was removed from SH1 by incubation with $10 \mathrm{mM}$ DTT at $4{ }^{\circ} \mathrm{C}$ overnight. The excess of the probe and DTT were removed on a PD10 column (Pharmacia). These labeled S1 samples are named as $\mathrm{S} 1(\mathrm{SH} 1, \mathrm{AEDANS})$ and $\mathrm{S} 1(\mathrm{SH} 1, \mathrm{AF})$, respectively. F-actin was labeled at Cys-374 with a 5-fold molar excess of eosin on ice for $2 \mathrm{~h}$, followed by the addition of an excess of DTT to stop the reaction. The labeled F-actin was extensively dialyzed against a buffer containing $0.2 \mathrm{mM}$ ATP, $2 \mathrm{mM} \mathrm{MgCl} 2,50 \mathrm{mM} \mathrm{KCl}$, and $2 \mathrm{mM}$ Tris- $\mathrm{HCl}, \mathrm{pH}$ 8.0 to remove the unreacted probe. The labeled F-actin was used within several days and immediately before fluorescence measurements was dialyzed against $2 \mathrm{mM} \mathrm{MgCl}_{2}, 50 \mathrm{mM}$ $\mathrm{KCl}$, and $2 \mathrm{mM}$ Tris- $\mathrm{HCl}, \mathrm{pH} 8.0$ to remove free nucleotide. The extent of labeling of myosin S1 and F-actin by the probes was estimated spectrophotometrically using the following extinction coefficients: $E_{337}^{1 \%}=6100 \mathrm{M}^{-1} \mathrm{~cm}^{-1}$ for IAEDANS, $E_{495}^{1 \%}=80000 \mathrm{M}^{-1} \mathrm{~cm}^{-1}$ for IAF, and $E_{519}^{1 \%}=$ $100000 \mathrm{M}^{-1} \mathrm{~cm}^{-1}$ for eosin. For this purpose, concentrations of labeled S1 were measured by the Bradford protein assay (34) using bovine serum albumin as a standard. The degrees of labeling of SH1 of myosin S1 were in the range of $0.7-1$ for both labels, while the labeling of $\mathrm{SH} 2$ was about 0.9 for IAEDANS and 0.5 for IAF. Fluorescence polarization $(P)$ of labeled proteins was routinely measured for two major reasons: (i) to test for the possibility of unreacted dye contamination, whose fluorescence is largely depolarized $(P$ $<0.005$ ) and (ii) to calculate the anisotropy of the attached dye, which is needed for FRET analysis. The specificity of the labeling on S1 was verified by measurements of both $\mathrm{Ca}^{2+}$-ATPase and $\mathrm{K}^{+}$/EDTA-ATPase activities and by a $12.5 \%$ SDS - polyacrylamide gel electrophoresis of partially trypsin-digested labeled S1 in which the fluorescence fragments were located on unstained gels under UV illumination
(20). The ATPase activities $\left(\mathrm{Ca}^{2+}\right.$ - and $\mathrm{K}^{+} /$EDTA-ATPase $)$ of $\mathrm{S} 1$ were measured by determination of inorganic phosphate release (35). The assays were carried out at room temperature in $50 \mathrm{mM}$ Tris- $\mathrm{HCl}(\mathrm{pH} 7.9), 2.5 \mathrm{mM}$ ATP, and either $0.23 \mathrm{M} \mathrm{KCl}$ and $2.5 \mathrm{mM} \mathrm{CaCl}_{2}$ for $\mathrm{Ca}^{2+}$-ATPase or $0.6 \mathrm{M} \mathrm{KCl}$ and $1 \mathrm{mM}$ EDTA for $\mathrm{K}^{+} /$EDTA-ATPase activities, using $0.1 \mathrm{mg} / \mathrm{mL}$ of protein. In agreement with previous reports $(20,36)$, the covalent modification of SH1 with IAEDANS displayed an increase in the $\mathrm{Ca}^{2+}$-ATPase activity by a factor of $2.4-3$ and an inhibition of the $\mathrm{K}^{+}$/ EDTA-ATPase activity of $90 \%$. When SH1 was modified by IAF, the $\mathrm{Ca}^{2+}$-ATPase activity was enhanced by a factor of 1.4-1.6 and the $\mathrm{K}^{+} /$EDTA-ATPase activity was inhibited by $45 \%$. S1 labeled at SH2 was inhibited in both the $\mathrm{Ca}^{2+}$ ATPase and $\mathrm{K}^{+}$/EDTA-ATPase activities, by at least 30 and $50 \%$, respectively. The fluorescence fragments of the partially digested labeled S1 were located on unstained SDSpolyacrylamide gels under UV illumination. The gels showed a single fluorescent band in the $20-\mathrm{kDa}$ peptide segment in which SH1 and SH2 are found.

Preparation of Stable S1 Transition State Complexes. The complexes $\mathrm{S} 1 \cdot \mathrm{ADP} \cdot \mathrm{VO}_{4}{ }^{3-}$ and $\mathrm{S} 1 \cdot \mathrm{ADP} \cdot \mathrm{AlF}_{4}{ }^{-}$were prepared with the labeled protein S1(AEDANS, SH2) and S1(AF, SH2) as previously described (22). Briefly, labeled S1 in $60 \mathrm{mM} \mathrm{KCl}, 25 \mathrm{mM}$ Hepes, pH 7.9 was incubated at 25 ${ }^{\circ} \mathrm{C}$ for 5 min with $1 \mathrm{mM} \mathrm{MgCl}, 0.2 \mathrm{mM}$ ADP, and, for $\mathrm{AlF}_{4}{ }^{-}$with $5 \mathrm{mM} \mathrm{NaF}$. Then, metavanadate solution (for $\mathrm{VO}_{4}{ }^{3-}$ ) or $\mathrm{AlCl}_{3}$ (for $\mathrm{AlF}_{4}{ }^{-}$) was added to a final concentration of $0.2 \mathrm{mM}$, and the incubation was continued for 90 $\min$ at $25{ }^{\circ} \mathrm{C}$. To remove excess of nucleotide analogues, the samples were passed through a PD-10 column (Pharmacia).

Fluorescence Measurements. Steady-state fluorescence measurements were performed in a continuously stirred cuvette with the following spectrofluorimeters: HitachiPerkin-Elmer (model 650-40) and SLM-4800C, with calibrated polarizers for polarization measurements. All experiments were performed at $25^{\circ} \mathrm{C}$ in a medium containing 20 $\mathrm{mM}$ Hepes, $\mathrm{pH} 7.0$ and $2.5 \mathrm{mM} \mathrm{MgCl} 2$. S1-AEDANS and S1-AF emissions were monitored at 470 and $520 \mathrm{~nm}$ with excitation at 336 and $490 \mathrm{~nm}$, respectively. The binding of vanadates to $\mathrm{S} 1$ was monitored by titration of modified $\mathrm{S} 1$ $(0.45 \mu \mathrm{M})$ with metavanadate or decavanadate solutions ranging from 0 to $50 \mu \mathrm{M}$ total vanadium concentration. Inner filter effects, due to the absorbance at 336 and $470 \mathrm{~nm}$ of metavanadate and decavanadate, were corrected using the following equation: $F_{\text {corr }}=C F_{\text {obs }}$, where $F_{\text {corr }}$ and $F_{\text {obs }}$ are the values of the corrected and observed fluorescence, respectively, and $C=$ antilog $\left[\left(A_{336}+A_{470}\right) / 2\right]$ (37), with the following extinction coefficients (determined under our experimental conditions from stock metavanadate and decavanadate solutions): $0.4 \mathrm{mM}^{-1} \mathrm{~cm}^{-1}$ for metavanadate at $336 \mathrm{~nm}$, and 1.12 and $0.09 \mathrm{mM}^{-1} \mathrm{~cm}^{-1}$ for decavanadate at 336 and $470 \mathrm{~nm}$, respectively. Eosin-F-actin fluorescence was measured with excitation and emission wavelengths set at 475 and $520 \mathrm{~nm}$, respectively.

Polarization of fluorescence was calculated by using the expression (38): $P(\lambda)=\left[\left(I_{\|}-G(\lambda) I_{\perp}\right) /\left(I_{\|}+G(\lambda) I_{\perp}\right)\right]$, where $I_{\|}$and $I_{\perp}$ are the fluorescence intensities measured with parallel and perpendicularly oriented polarizers, respectively, and $G(\lambda)$ is the correction factor for the polarization characteristics of the emission monochromator. For each 
excitation/emission setup the value of $G(\lambda)$ was averaged from more than 10 measurements, and for the polarization measurements done in this work it was $1.085 \pm 0.005$ (IAEDANS -S1) and $1.140 \pm 0.005$ (IAF-S1). The steadystate anisotropy of fluorescence, $r_{\mathrm{s}}$, has been calculated from the measured polarization $(P)$ by using the equation $(38)$ : $r_{\mathrm{s}}=2 P /(3-P)$.

Dissociation constants were obtained using the program Origin 5.0, from the slopes of the linear least-squares fit of the fluorescence titration data to the Scatchard equation, taking the fractional change of fluorescence (or anisotropy for mant-AMPPNP titration) as the fraction of saturated binding sites $(\beta)$. Thus, bound ligand concentration: [bound] $=n \beta[\mathrm{S} 1]$, where $n=$ number of binding sites/S1 monomer; and free ligand concentration: [free] $=$ [total ligand $]-$ [bound].

Analysis of Fluorescence Energy Transfer (FRET). The calculations of distances from steady-state fluorescence energy transfer measurements have been done using the basic equation for one donor/acceptor pair (39). The distance $R_{0}$ for the pairs IAF-S1/eosin-F-actin and IAEDANS $-\mathrm{S} 1 / \mathrm{V}_{10}$ has been calculated as in Gutiérrez-Merino et al. (40), with the equation (41):

$$
R_{0}=9.76 \times 10^{3}\left(J \eta^{-4} \kappa^{2} Q_{\mathrm{D}}\right)^{1 / 6}(\AA)
$$

using a value for $\kappa^{2}=2 / 3$ (which corresponds to a random orientation between donor and acceptor), with a refractive index $\eta=1.33$, i.e., equal to that of a dilute aqueous solution, and with the donor quantum yield measured for IAF-S1 $\left(Q_{\mathrm{D}}=0.35 \pm 0.05\right)$ and IAEDANS $-\mathrm{S} 1\left(Q_{\mathrm{D}}=0.18 \pm 0.03\right)$ using $1 \mathrm{mM}$ quinine sulfate in $1 \mathrm{~N}$ sulfuric acid at $25^{\circ} \mathrm{C}$ as a reference standard, as in Centeno and Gutiérrez-Merino (42). The overlap integral values were calculated from the absorption and corrected emission spectra of the acceptor and donor, respectively, as in previous papers $(40,42)$.

Light-Scattering Measurements. Light scattering intensity was monitored at $90^{\circ}$ with respect to the incident light at 25 ${ }^{\circ} \mathrm{C}$, using a Perkin-Elmer 650-40 spectrofluorimeter. Both monochromators were set at $400 \mathrm{~nm}$ for the polymerization measurements of actin or at $500 \mathrm{~nm}$ (to avoid inner filter effects by decavanadate) for the experiments with $\mathrm{S} 1$ and F-actin/S1 complex.

\section{RESULTS}

Inhibition of the Actin Stimulated S1 ATPase Activity by $V_{10}$. Addition of decavanadate produced inhibition of the actin-stimulated myosin S1 ATPase activity (Table 1). The inhibition is attained in less than $15 \mathrm{~s}$, as shown by the linearity of the kinetic traces of the ATPase activity after manual mixing since the starting point and for a period lasting more than $10 \mathrm{~min}$. As metavanadate (up to $150 \mu \mathrm{M}$ of total vanadium concentration) produced less than $20 \%$ inhibition of this activity, these results also showed that decavanadate remains stable in the assay medium for, at least, $30 \mathrm{~min}$, in good agreement with our measurements of the stability of decavanadate determined from the absorbance at $400 \mathrm{~nm}$ of decavanadate solutions in $20 \mathrm{mM}$ Hepes, $\mathrm{pH}$ 7.0 (see Materials and Methods).

Increasing the F-actin concentration from 0.5 to $4 \mu \mathrm{M}$, while keeping the $\mathrm{S} 1$ concentration fixed to $0.45 \mu \mathrm{M}$ in the ATPase assay, did not increase the concentration of $\mathrm{V}_{10}$
Table 1: Effect of Actin Concentration on $\mathrm{V}_{10}$ Inhibition Constants of Myosin S1 ATPase Activity ${ }^{a}$

\begin{tabular}{cc}
\hline [actin] $(\mu \mathrm{M})$ & $\mathrm{IC}_{50}(\mu \mathrm{M})$ \\
\hline 0 & $12.5 \pm 0.25$ \\
0.5 & $0.75 \pm 0.06$ \\
1.0 & $0.60 \pm 0.06$ \\
2.0 & $0.58 \pm 0.06$ \\
4.0 & $0.55 \pm 0.05$
\end{tabular}

${ }^{a}$ The assays were performed at $25^{\circ} \mathrm{C}$ using a coupled enzyme system (as described in Materials and Methods) with $0.45 \mu \mathrm{M} \mathrm{S} 1$ in $20 \mathrm{mM}$ Hepes (pH 7.0), $2 \mathrm{mM}$ ATP, and $2.5 \mathrm{mM} \mathrm{MgCl} 2$. Decavanadate final concentrations ranging from 0 to $100 \mu \mathrm{M}$ (total vanadium concentration) were added to the medium, from a decavanadate stock solution of 5 or $50 \mathrm{mM} . \mathrm{IC}_{50}$ values are the average of the results obtained with at least three different S1 and F-actin preparations.

required to produce $50 \%$ inhibition $\left(\mathrm{IC}_{50}\right)$ of actin-stimulated S1-ATPase activity, but at most slightly decreased it from $0.75 \pm 0.07$ to $0.55 \pm 0.05 \mu \mathrm{M}$ of $\mathrm{V}_{10}$ when F-actin increased from 0.5 to $4 \mu \mathrm{M}$ (Table 1 ). Therefore, we can exclude that this inhibition is the result of a direct competition between F-actin and decavanadate for binding to S1. Consistently, $\mathrm{V}_{10}$ was also found to inhibit the S1-ATPase activity in the absence of F-actin, but with an $\mathrm{IC}_{50}$ value of $12.5 \mu \mathrm{M}$, i.e., approximately 20-fold higher than that obtained in the presence of $2-4 \mu \mathrm{M}$ F-actin. These results suggested that the binding site of $\mathrm{V}_{10}$ which accounted for inhibition of the S1-ATPase activity is likely to be located near the functional protein domains altered upon F-actin binding to S1, e.g., the catalytic or the energy transduction domain connecting catalytic and F-actin binding sites (8).

To question the possibility that the inhibition of the actinstimulated S1-ATPase activity by $\mathrm{V}_{10}$ can be due to competition with the substrate ATP, we have studied the inhibition of actin-stimulated S1-ATPase at different ATP concentrations. The obtained results are presented in Figure 1 in the form of Hanes plots, and showed that the inhibition by $V_{10}$ is noncompetitive with ATP, yielding an inhibition constant $\left(K_{\mathrm{i}}\right)$ of $0.27 \pm 0.05 \mu \mathrm{M} \mathrm{V}_{10}(2.7 \pm 0.5 \mu \mathrm{M}$ total vanadium concentration). Owing to the relevance of this point, we have studied the effect of $\mathrm{V}_{10}$ on the binding of ATP to S1, which has been monitored from the increase of anisotropy of a mant-fluorescent ATP analogue upon binding to S1, as in ref 43. To avoid ATP hydrolysis during these binding studies, we have used the non-hydrolysable mant-AMPPNP analogue instead of mant-ATP. The results are presented in the Figure 2 , and analyzed with Scatchard plots using the fractional increase of fluorescence anisotropy $\left[\left(r-r_{\min }\right) /\left(r_{\max }-r_{\min }\right)\right]$ as the molar fraction of bound mant-AMPPNP (inset of Figure 2). From the slopes of the linear least-squares fit of the Scatchard plots of these data, the following values for the dissociation constant of mant-AMPPNP were obtained ( $R>0.96$ in all the cases): $0.23 \pm 0.02 \mu \mathrm{M}$ (in the absence of $\mathrm{V}_{10}$ ), $0.26 \pm 0.02$ and $0.23 \pm 0.02 \mu \mathrm{M}$ (in the presence of 5 and $10 \mu \mathrm{M}$ of $\mathrm{V}_{10}$ ). Thus, $\mathrm{V}_{10}$ binding to $\mathrm{S} 1$ is noncompetitive with ATP binding.

These results showed that the inhibition of actin-stimulated S1-ATPase activity by $V_{10}$ is the result of slowing down the catalytic cycle by binding at a regulatory site different from the nucleotide site of the catalytic center. Because the $\mathrm{IC}_{50}$ value for inhibition by decavanadate of the actin-stimulated $\mathrm{S} 1$-ATPase corresponds to a $\mathrm{V}_{10} / \mathrm{S} 1$ molar ratio of $1.0-1.5 /$ 1 , we studied the dependence of the $\mathrm{IC}_{50}$ value with $\mathrm{S} 1$ 

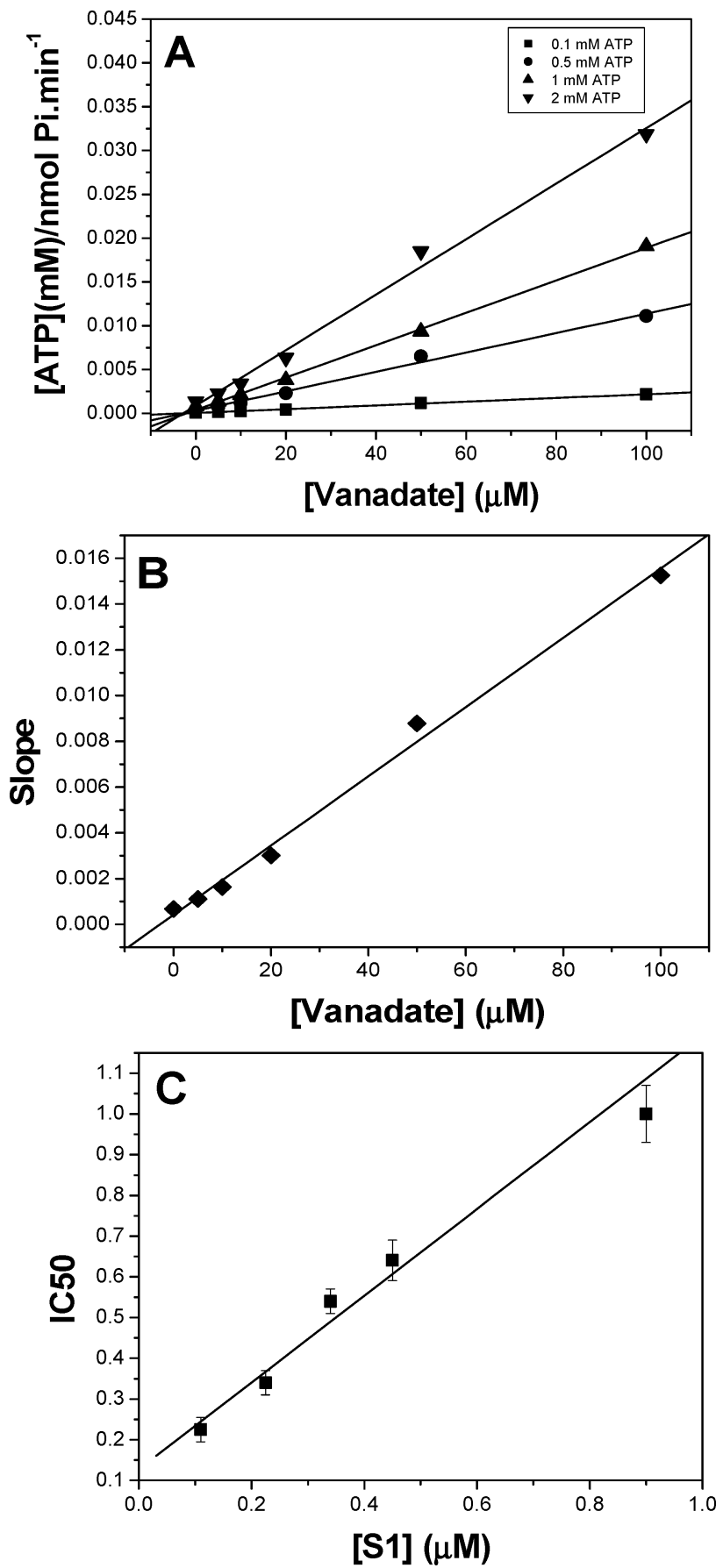

FIGURE 1: Inhibition by decavanadate of actin-stimulated $\mathrm{S} 1 \mathrm{Mg}^{2+}-$ ATPase activity. The assays were performed at $25{ }^{\circ} \mathrm{C}$, in $20 \mathrm{mM}$ Hepes, $25 \mathrm{mM} \mathrm{KCl}$ and $2.5 \mathrm{mM} \mathrm{MgCl} 2$ (pH 7.0). (A) Hanes plot of $[\mathrm{ATP}] / v$ versus vanadate concentrations up to $100 \mu \mathrm{M}$ in total vanadium added (i.e., up to $10 \mu \mathrm{M} \mathrm{V}_{10}$ ) for ATP concentrations of $0.1 \mathrm{mM}$ (squares), $0.5 \mathrm{mM}$ (circles), $1 \mathrm{mM}$ (up triangles), and 2 $\mathrm{mM}$ (down triangles). The studies were carried out with $0.45 \mu \mathrm{M}$ S1 and $2 \mu \mathrm{M}$ actin. (B) The plot was made with the slopes obtained from the Hanes plot versus [vanadate] to calculate the $K_{\mathrm{i}}$ value from the intercept of the ordinate. (C) Dependence of the $\mathrm{IC}_{50}$ (concentration of decavanadate producing $50 \%$ inhibition of actinstimulated S1 $\mathrm{Mg}^{2+}$-ATPase activity) with $2 \mathrm{mM}$ ATP and S1 concentration $(0.11-0.9 \mu \mathrm{M})$, maintaining a constant actin/S1 concentration ratio of 4.4 .

concentration, maintaining the ratio of actin/S1 concentrations constant. The $\mathrm{IC}_{50}$ was linearly dependent upon the $\mathrm{S} 1$ concentration yielding a slope of $1.06 \pm 0.12 \mu \mathrm{M} \mathrm{V} \mathrm{V}_{10} / \mu \mathrm{M}$ S1 (Figure 1C), thus showing that it is caused by the binding

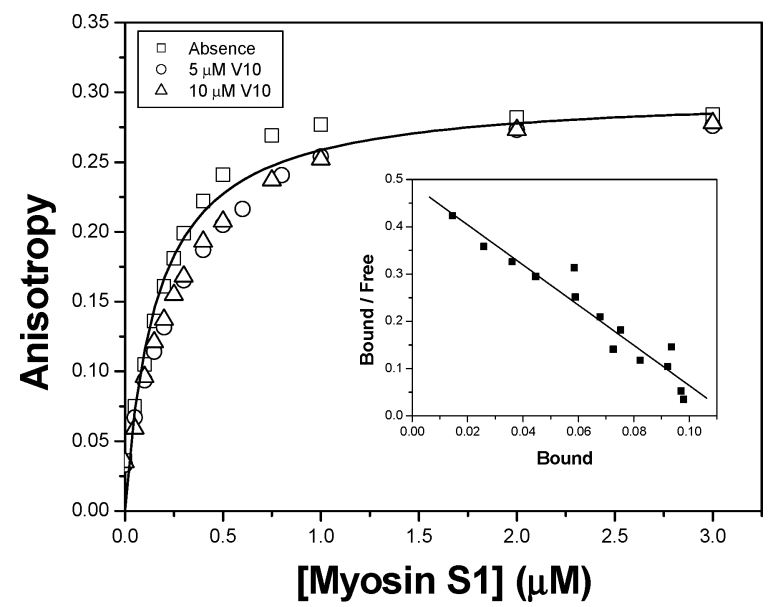

FIGURE 2: Fluorescence anisotropy titration of $0.1 \mu \mathrm{M}$ mantAMPPNP with myosin-S1 concentrations ranging from 0.05 to 3 $\mu \mathrm{M}$, in the absence (squares) and presence of $5 \mu \mathrm{M}$ (circles) and $10 \mu \mathrm{M}$ (triangles) $\mathrm{V}_{10}$ concentrations. Dissociation constants were determined from the slopes of the linear least-squares fit of the Scatchard plots (inset plot). Fluorescence measurements (excitation wavelength $357 \mathrm{~nm}$; emission wavelength $447 \mathrm{~nm}$ ) were carried out at $25^{\circ} \mathrm{C}$, in $20 \mathrm{mM}$ Hepes, $25 \mathrm{mM} \mathrm{KCl}$ and $2.5 \mathrm{mM} \mathrm{MgCl}_{2}$ (pH 7.0).

of $\mathrm{V}_{10}$ species to one inhibitory high-affinity site per molecule of myosin $\mathrm{S} 1$.

Location of the Binding Site of $V_{10}$ that Produced Inhibition of the Actin Stimulated S1-ATPase Activity. Recently (18), we have shown the presence of a high-affinity binding site for $\mathrm{V}_{10}$ in myosin from intrinsic fluorescence quenching studies. Nevertheless, the possibility that the inhibition of the actin-stimulated myosin ATPase activity could be due to $\mathrm{V}_{10}$ binding to $\mathrm{F}$-actin instead to myosin or to impairment of the interaction between myosin and F-actin cannot be excluded solely on these grounds.

However, the possibility of a direct interaction of $\mathrm{V}_{10}$ with F-actin can be discarded because decavanadate (up to 200 $\mu \mathrm{M}$ total vanadium): (i) had no effect on the fluorescence of F-actin-eosin nor on the intrinsic fluorescence of F-actin; (ii) had no effect on the light scattering of F-actin (thus implying that it does not promote F-actin dissociation); and (iii) had no effect on the rate of F-actin polimerization (measured using the light scattering approach, as in Cooper and Pollard (44) (results not shown).

Therefore, we decided to gain a deeper knowledge of the interaction of decameric vanadate with its high-affinity binding site in myosin S1. To this end, we have labeled Cys707 of S1 with IAEDANS and with IAF following established protocols as indicated in Materials and Methods. $\mathrm{V}_{10}$ was found to inhibit the actin-stimulated S1-ATPase activity of labeled $\mathrm{S} 1$, but with $\mathrm{IC}_{50}$ values higher than that obtained for control S1 $\left(0.7 \pm 0.1 \mu \mathrm{M} \mathrm{V} \mathrm{V}_{10}\right)$, namely, $1.6 \pm 0.2 \mu \mathrm{M}$ for S1(AF, SH2) and $8.9 \pm 1.3 \mu \mathrm{M}$ for S1(AEDANS, SH2). These results suggested functional interaction between SH1 and $\mathrm{V}_{10}$ binding sites. The results of the titration of the fluorescence of labeled S1(AEDANS, SH2) and of S1(AF, $\mathrm{SH} 2)$ with decavanadate are shown in Figure 3A. The relatively large magnitude of the fluorescence changes found at saturation with $\mathrm{V}_{10}$ (Figure $3 \mathrm{~A}$ ) suggested a close proximity between the binding site for $\mathrm{V}_{10}$ and Cys-707. Control experiments carried out with IAEDANS-Cys and IAF-Cys showed that $\mathrm{V}_{10}$ did not affect directly the fluo- 

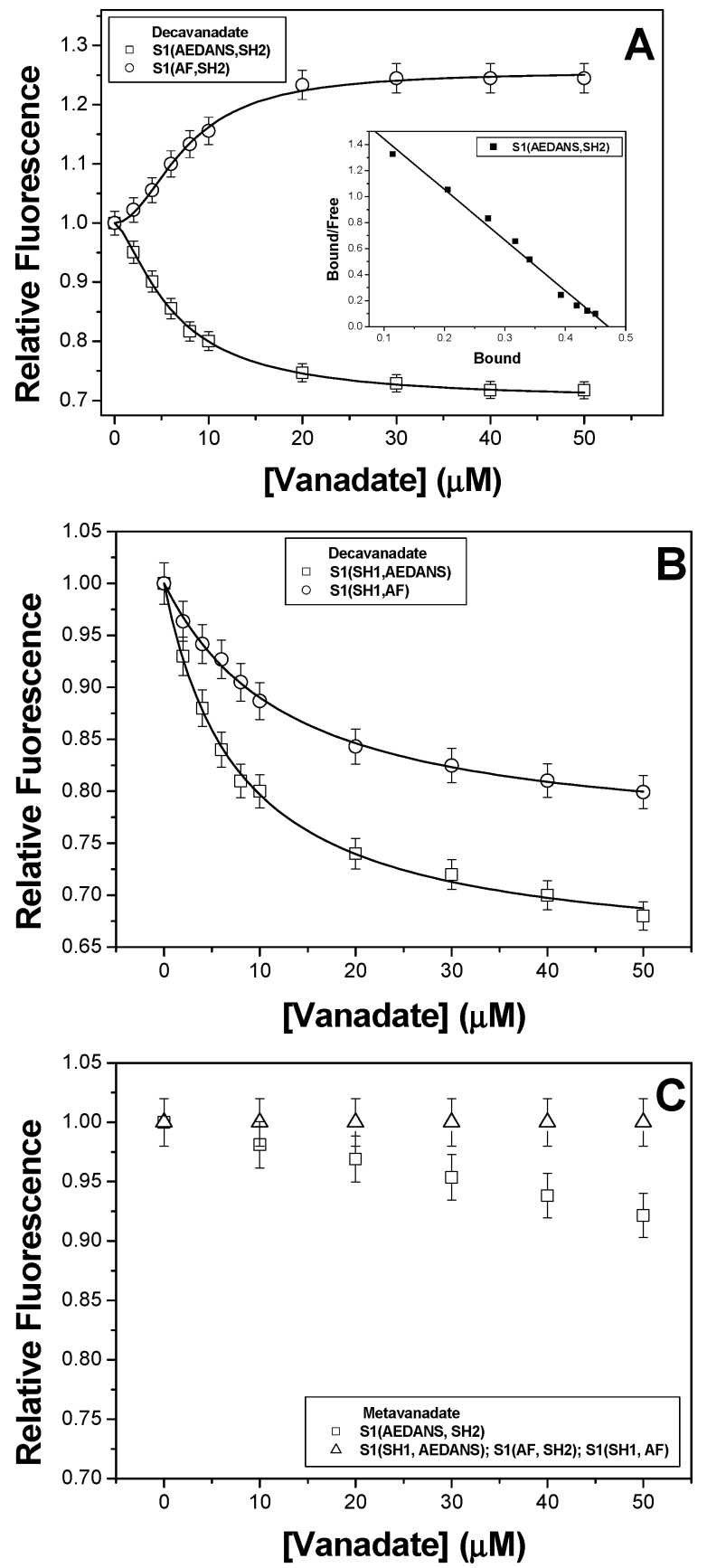

FIGURE 3: Dependence of the fluorescence of labeled S1 upon decavanadate (A and B) and metavanadate (C) concentration. $Y$-axis: fluorescence relative to the fluorescence in the absence of decavanadate or metavanadate. Small volumes of vanadate solutions were successively added to $0.45 \mu \mathrm{M}$ of labeled S1 from 5 or 50 $\mathrm{mM}$ decavanadate or metavanadate stock solutions. In panels A (S1 labeled at SH1 - Cys 707) and B (S1 labeled at SH2 - Cys 697), squares and circles represent the labeling with IAEDANS and IAF, respectively. In panel $\mathrm{C}$, squares represent the labeling with IAEDANS at SH1 residue and triangles the labeling with IAEDANS at $\mathrm{SH} 2$ and IAF at $\mathrm{SH} 1$ and $\mathrm{SH} 2$ residues. Dissociation constants were determined from the slopes of the linear least-squares fit of the Scatchard plots (see for example inset plot of panel A). All measurements were made at $25^{\circ} \mathrm{C}$ in a medium containing 20 mM Hepes ( $\mathrm{pH} 7.0$ ), $25 \mathrm{mM} \mathrm{KCl}, 2.5 \mathrm{mM} \mathrm{MgCl}_{2}$. IAEDANS and IAF fluorescence were measured with emission wavelengths of 470 and $517 \mathrm{~nm}$, and with excitation wavelengths of 336 and $490 \mathrm{~nm}$, respectively.

rescence of these dyes (less than $2 \%$ effect up to $200 \mu \mathrm{M}$ $\mathrm{V}_{10}$ ). These results showed that $\mathrm{V}_{10}$ produced partial quench- ing of the fluorescence of S1(AEDANS, $\mathrm{SH}_{2}$ ) and increase of the fluorescence of $\mathrm{S} 1\left(\mathrm{AF}, \mathrm{SH}_{2}\right)$ with saturation characteristics of the ligand binding to a protein. Titration with $\mathrm{V}_{10}$ at different concentrations of labeled $\mathrm{S} 1$ (results not shown) showed that the concentration of $\mathrm{V}_{10}$ producing $50 \%$ of the maximum fluorescence change can be fit to a straight line with a slope of $1.0 \pm 0.1 \mu \mathrm{M} \mathrm{V}_{10}$ species $/ \mu \mathrm{M} \mathrm{S} 1$, thus confirming that fluorescence quenching is the result of binding of $\mathrm{V}_{10}$ to a single site per mole of S1. Given that in previous NMR studies (29) it was shown that upon dilution to the reaction medium, the decavanadate solutions can contain approximately $10 \%$ of orthovanadate, to ascertain whether the orthovanadate added with decavanadate solution can account for the effects on the fluorescence shown in Figure $3 \mathrm{~A}$, we have carried out titration with a metavanadate solution (containing only orthovanadate) of the fluorescence of S1(AEDANS, $\mathrm{SH}_{2}$ ) and of S1(AF, $\mathrm{SH}_{2}$ ) (Figure 3C). The results showed that the contaminant orthovanadate cannot account for the fluorescence changes produced by titration with decavanadate solutions. Because the fractional fluorescence change $\left(\Delta F / \Delta F_{\max }\right)$ can be taken as the fraction of occupied $\mathrm{V}_{10}$ binding sites, bound and free $\mathrm{V}_{10}$ were calculated from the results of the titration with $\mathrm{V}_{10}$ of the fluorescence of $\mathrm{S} 1$ (AEDANS, $\mathrm{SH}_{2}$ ) with one binding site per molecule of S1 (see above). From the slopes of Scatchard plots of the data (see for example inset of Figure $3 \mathrm{~A}$ ), we have obtained the following dissociation constants $\left(K_{\mathrm{d}}\right)$ for $\mathrm{V}_{10}: 0.26 \pm 0.02 \mu \mathrm{M}$ for S1(AEDANS, $\mathrm{SH}_{2}$ ) and $0.16 \pm$ $0.05 \mu \mathrm{M}$ for $\mathrm{S} 1\left(\mathrm{AF}, \mathrm{SH}_{2}\right)$. These values for the dissociation constant of $\mathrm{V}_{10}$ from $\mathrm{S} 1$ are identical, for $\mathrm{S} 1$ (AEDANS, $\mathrm{SH}_{2}$ ), or close, for $\mathrm{S} 1\left(\mathrm{AF}, \mathrm{SH}_{2}\right)$, to the $K_{\mathrm{i}}$ value of inhibition of actin-stimulated unlabeled S1-ATPase activity obtained from Hanes plots, $0.27 \pm 0.05 \mu \mathrm{M}$ (see above). This indicated that binding of $\mathrm{V}_{10}$ is not significantly altered by $\mathrm{AF}$ or AEDANS labeling of Cys-707, and suggested that the observed increase of $\mathrm{IC}_{50}$ for $\mathrm{V}_{10}$ in S1(AEDANS, SH2) or $\mathrm{S} 1(\mathrm{AF}, \mathrm{SH} 2)$ is related to the alteration of the catalytic cycle produced by $\mathrm{S} 1$ labeling.

To further assess this point, we labeled $\mathrm{S} 1$ at the "so-called" $\mathrm{SH}_{2}$ group (Cys-697), which is also located in this protein domain (45), with IAEDANS and IAF (as indicated in Materials and Methods) and carried out the titration of $\mathrm{S} 1\left(\mathrm{SH}_{1}, \mathrm{AEDANS}\right)$ and $\mathrm{S} 1\left(\mathrm{SH}_{1}, \mathrm{AF}\right)$ with $\mathrm{V}_{10}$. Cys-697 labeling with IAEDANS or with IAF was found to have no effect on the $\mathrm{IC}_{50}$ value for $\mathrm{V}_{10}$ inhibition of actinstimulated S1 ATPase activity. The results are presented in the Figure 3B, and the Scatchard plot of the data yielded the following $K_{\mathrm{d}}$ values for $\mathrm{V}_{10}: 0.40 \pm 0.02$ and $0.70 \pm$ $0.04 \mu \mathrm{M}$ for $\mathrm{S} 1\left(\mathrm{SH}_{1}, \mathrm{AEDANS}\right)$ and $\mathrm{S} 1\left(\mathrm{SH}_{1}, \mathrm{AF}\right)$, i.e., between 1.5 and 3 -fold higher than the $K_{\mathrm{i}}$ obtained from Hanes plots and close to those obtained from the data shown in Figure 3A. Therefore, labeling at the $\mathrm{SH}_{2}$ group with AEDANS or AF decreased the free energy of $\mathrm{V}_{10}$ binding to the inhibitory site $\left[\Delta G=R T \ln \left(K_{\mathrm{d} 1} / K_{\mathrm{d} 2}\right)\right]$ by nearly 0.6 $\mathrm{kcal} / \mathrm{mol}$, indicating only a small distortion of the $\mathrm{V}_{10}$ binding site. Again, the data shown in Figure $3 \mathrm{C}$ ruled out any significant contribution of orthovanadate to the quenching of the fluorescence of $\mathrm{S} 1\left(\mathrm{SH}_{1}, \mathrm{AEDANS}\right)$ and $\mathrm{S} 1\left(\mathrm{SH}_{1}, \mathrm{AF}\right)$ produced by titration with $\mathrm{V}_{10}$.

The affinity of $\mathrm{V}_{10}$ for this site in $\mathrm{S} 1$ is strongly dependent upon ionic strength, showing the relevance of electrostatic interactions for decameric vanadate binding to $\mathrm{S} 1$, and that 
Table 2: Effect of Different Myosin Modulators on the Dissociation Constant of Decameric Vanadate to S1(AEDANS, SH2) and to $\mathrm{S} 1(\mathrm{AF}, \mathrm{SH} 2)^{a}$

\begin{tabular}{lcc}
\hline & \multicolumn{2}{c}{$K \mathrm{~d}(\mu \mathrm{M})$} \\
\cline { 2 - 3 } modulators & S1-AEDANS & S1-AF \\
\hline none & $0.26 \pm 0.03$ & $0.16 \pm 0.04$ \\
ADP-V & $0.45 \pm 0.05$ & $0.25 \pm 0.03$ \\
ADP-AlF $_{4}$ & $0.62 \pm 0.07$ & $0.46 \pm 0.05$ \\
\hline
\end{tabular}

${ }^{a}$ AEDANS and AF fluorescence were measured at $25{ }^{\circ} \mathrm{C}$ with emission wavelengths of 470 and $517 \mathrm{~nm}$, and excitation wavelengths of 336 and $490 \mathrm{~nm}$, respectively, in $20 \mathrm{mM}$ Hepes, $2.5 \mathrm{mM} \mathrm{MgCl}$, and $25 \mathrm{mM} \mathrm{KCl}(\mathrm{pH} 7.0)$. Decavanadate final concentrations ranging from 0 to $100 \mathrm{mM}$ (total vanadium concentration) were added to the medium, from a decavanadate stock solution of 5 or $50 \mathrm{mM} . K_{\mathrm{d}}$ values were obtained from Scatchard plots of the fractional fluorescence change, as indicated in the text, and are the average of at least triplicate experiments.

at a close to physiological ionic strength $(0.2 \mathrm{M} \mathrm{KCl})$ the $\mathrm{IC}_{50}$ for inhibition of the actin-stimulated myosin ATPase activity by $\mathrm{V}_{10}$ is below $2.5 \mu \mathrm{M}$ (results not shown).

Effect of Different Myosin ATPase Modulators on the Interaction of $V_{10}$ with $S 1$. As the results shown above indicated that the inhibition of actin-stimulated S1-ATPase activity by $\mathrm{V}_{10}$ is noncompetitive either with actin or with ATP, we considered next that the affinity for $\mathrm{V}_{10}$ of different conformational states of $\mathrm{S} 1$, which become populated during the catalytic cycle $(46-48)$, can be significantly different. To this end, $\mathrm{ADP} \cdot \mathrm{V}_{1}$ and $\mathrm{ADP} \cdot \mathrm{AlF}_{4}$ complexes were prepared with labeled $\mathrm{S} 1$ to mimic the intermediate activated $\mathrm{S} 1^{* *} \cdot \mathrm{ADP} \cdot \mathrm{P}_{\mathrm{i}}$ state, as described elsewhere $(22,23)$. The results of titration with $\mathrm{V}_{10}$ of the fluorescence of S1(AEDANS, $\mathrm{SH}_{2}$ ) and of $\mathrm{S} 1\left(\mathrm{AF}, \mathrm{SH}_{2}\right.$ ) pointed out that (i) although $\mathrm{ADP} \cdot \mathrm{V}_{1}$ and $\mathrm{ADP} \cdot \mathrm{AlF}_{4}$ produced partial quenching of the fluorescence of S1(AEDANS, $\mathrm{SH}_{2}$ ) (as previously reported in ref 23), $\mathrm{V}_{10}$ binding produced an additional quenching of this fluorescence, which at saturation is the same as that found in absence of $\mathrm{ADP} \cdot \mathrm{V}_{1}$ or $\mathrm{ADP} \cdot \mathrm{AlF}_{4}$; (ii) at saturation of $\mathrm{V}_{10}$ the increase of $\mathrm{S} 1\left(\mathrm{AF}, \mathrm{SH}_{2}\right)$ fluorescence in the presence of $\mathrm{ADP} \cdot \mathrm{V}_{1}$ or $\mathrm{ADP} \cdot \mathrm{AlF}_{4}$ is about $20 \%$ higher than that obtained in absence of the nucleotide complex $\mathrm{ADP} \cdot \mathrm{V}_{1}$ or $\mathrm{ADP} \cdot \mathrm{AlF}_{4}$ (which produced approximately $20 \%$ quenching of the fluorescence of $\mathrm{S} 1\left(\mathrm{AF}, \mathrm{SH}_{2}\right)$; and (iii) in the presence of $\mathrm{ADP} \cdot \mathrm{V}_{1}$ or $\mathrm{ADP} \cdot \mathrm{AlF}_{4}$ the dissociation constant of $\mathrm{V}_{10}$ from $\mathrm{S} 1$ is only weakly increased (Table 2). In addition, the results obtained with $\mathrm{S} 1$ (AEDANS, $\mathrm{SH}_{2}$ ) demonstrated that $\mathrm{V}_{10}$ species do not bind to the catalytic site, as the extent of quenching produced at saturation with $\mathrm{V}_{10}$ is not affected by the presence of $\mathrm{ADP} \cdot \mathrm{V}_{1}$ or $\mathrm{ADP} \cdot \mathrm{AlF}_{4}$, and for $\mathrm{S} 1\left(\mathrm{AF}, \mathrm{SH}_{2}\right)$ the effect of decavanadate (increase of fluorescence) is opposite to the effect of $\mathrm{ADP} \cdot \mathrm{V}_{1}$ or $\mathrm{ADP} \cdot$ $\mathrm{AlF}_{4}$ (quenching).

$\mathrm{AP}_{5} \mathrm{~A}$ has been shown to bind to $\mathrm{S} 1$ and to actomyosin in myofibrils and skinned fibers in a bimodal way that extends from the nucleotide binding site at the catalytic crevice through the "so-called" phosphate tube and to the 50-K cleft leading to the back door of the catalytic center (49). Because, the helix connecting Cys-707 and Cys-697 is at the bottom of the $50-\mathrm{K}$ cleft leading to the back door of the catalytic center (50), and the results shown above suggested a close proximity between the binding site for $\mathrm{V}_{10}$ and labels covalently bound to these cysteines, we decided to question whether binding of $\mathrm{V}_{10}$ compete with $\mathrm{AP}_{5} \mathrm{~A}$, through binding
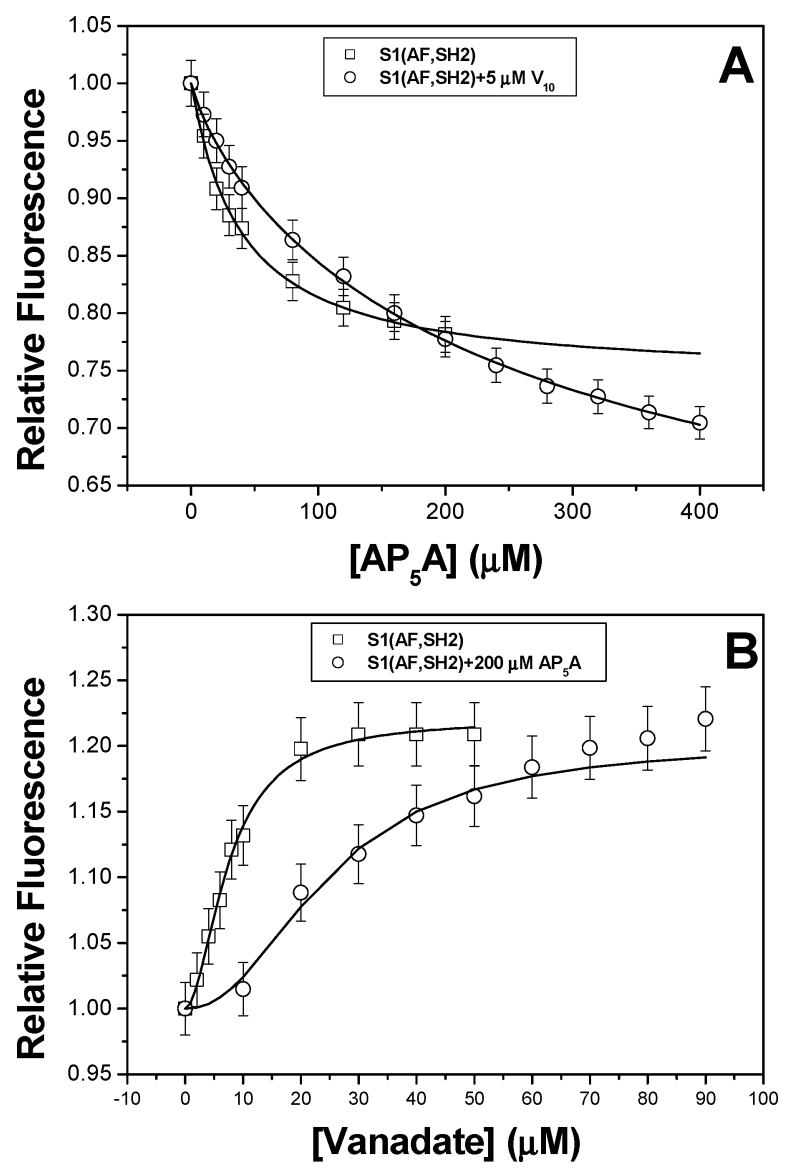

FIGURE 4: Dependence of the fluorescence of S1(AF,SH2) upon $\mathrm{AP}_{5} \mathrm{~A}(\mathrm{~A})$ and decavanadate (B) concentration. IAF fluorescence (excitation wavelength $490 \mathrm{~nm}$; emission wavelength $517 \mathrm{~nm}$ ) was measured at $25^{\circ} \mathrm{C}$, in $20 \mathrm{mM}$ Hepes (pH 7.0), $25 \mathrm{mM} \mathrm{KCl}$ and $2.5 \mathrm{mM} \mathrm{MgCl}_{2}$. Panel A: Titration with $\mathrm{AP}_{5} \mathrm{~A}$ of the fluorescence of $\mathrm{S} 1$ (AF,SH2) in the absence (squares) or presence (circles) of 5 $\mu \mathrm{M} \mathrm{V}_{10}(50 \mu \mathrm{M}$ total vanadium added as decavanadate). Panel B: Titration with decavanadate of the fluorescence of $\mathrm{S} 1(\mathrm{AF}, \mathrm{SH} 2)$ in the absence (squares) or presence (circles) of $200 \mu \mathrm{M} \mathrm{AP}{ }_{5} \mathrm{~A}$.

to a site close to the back door of the catalytic center. Titration of the fluorescence of $\mathrm{S} 1\left(\mathrm{AF}, \mathrm{SH}_{2}\right)$ with $\mathrm{AP}_{5} \mathrm{~A}$ allows to monitor the binding of $\mathrm{AP}_{5} \mathrm{~A}$ (Figure $4 \mathrm{~A}$ ), and the slopes of the Scatchard plots of these data yielded values for the $K_{\mathrm{d}}$ of the $\mathrm{AP}_{5} \mathrm{~A} / \mathrm{S} 1$ complex of $37 \pm 2 \mu \mathrm{M} \mathrm{AP} \mathrm{AP}_{5} \mathrm{in}$ the absence of $\mathrm{V}_{10}$ and $133 \pm 5 \mu \mathrm{M} \mathrm{AP}_{5} \mathrm{~A}$ in the presence of $5 \mu \mathrm{M} \mathrm{V}_{10}$, i.e., $50 \mu \mathrm{M}$ total vanadium (Figure $4 \mathrm{~A}$ ). The $K_{\mathrm{d}}$ of the $\mathrm{V}_{10} \cdot \mathrm{S} 1$ complex obtained from the slopes of the Scatchard plots of the data shown in the Figure 4B increased from $0.16 \pm 0.04 \mu \mathrm{M} \mathrm{V}_{10}$ in absence of $\mathrm{AP}_{5} \mathrm{~A}$ to $5.8 \pm 0.2$ $\mu \mathrm{M} \mathrm{V}_{10}$ in the presence of $200 \mu \mathrm{M} \mathrm{AP}_{5} \mathrm{~A}$. Thus, $\mathrm{V}_{10}$ and $\mathrm{AP}_{5} \mathrm{~A}$ compete for binding to $\mathrm{S} 1$.

Effect of $V_{10}$ on the SI/F-Actin Association. The effect of $\mathrm{V}_{10}$ on the light scattering of the acto-S1 complex solution is shown in the Figure 5. In the absence of ATP, there is only a small change on the light scattering of the complex (amounting to less than 10\%) at $\mathrm{V}_{10}$ concentrations that produced more than $80 \%$ inhibition of the actin-stimulated S1-ATPase activity, with no indications of dissociation of the acto-S1 complex (the effect of addition of ATP is included to illustrate this point). However, $\mathrm{V}_{10}$ but not orthovanadate produced a large increase in the time needed to reassociate $\mathrm{S} 1$ and actin after consumption of added ATP (compare Figure 5, panels B and C), and this increase is 

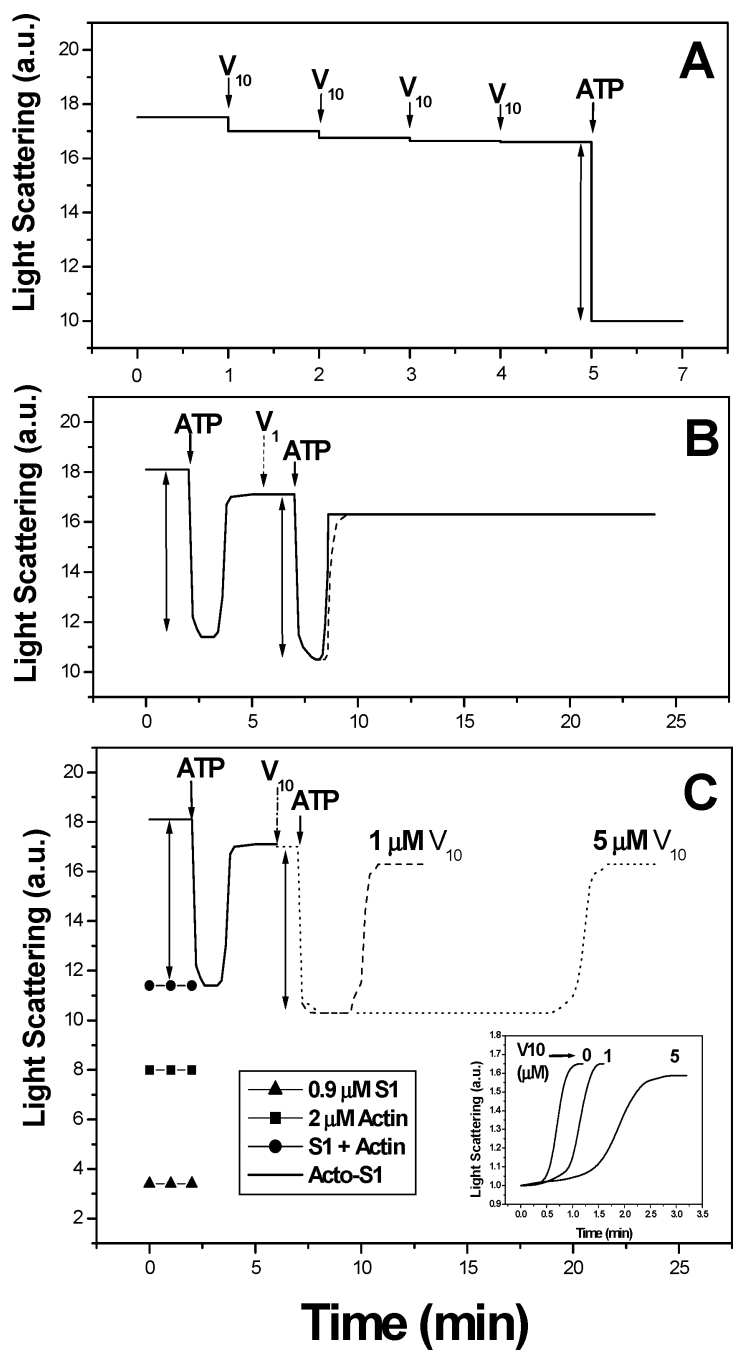

FIGURE 5: Effect of decameric vanadate on the dissociation and aggregation of the acto-S1 complex. (A) Light scattering of the acto-S1 complex (solid line) upon sequential additions of $5 \mu \mathrm{M}$ $\mathrm{V}_{10}(50 \mu \mathrm{M}$ total vanadium added as decavanadate) plus $0.25 \mathrm{mM}$ ATP. (B) Light scattering of the acto-S1 complex upon ATP $(0.25$ $\mathrm{mM}$ ) addition in the absence (solid line) or presence of $50 \mu \mathrm{M}$ metavanadate (dash line). (C) Light scattering of the acto-S1 complex upon ATP $(0.25 \mathrm{mM})$ addition in the absence (solid line) or presence of $1 \mu \mathrm{M}$ (dash line) and $5 \mu \mathrm{M}$ (dot line) $\mathrm{V}_{10}$, i.e., 10 and $50 \mu \mathrm{M}$ total vanadium added as decavanadate, respectively. Light scattering intensity at $90^{\circ}$ with respect to the incident light was measured with monochromators set at $500 \mathrm{~nm}$, and is given in arbitrary units (a.u.). The line joining circles denotes the sum of S1 (triangles) plus actin (squares) light scattering intensities, and the large double-headed arrows is the expected decrease of light scattering for a $100 \%$ ATP-induced dissociation of the actin-S1 complex. The recovery of the light scattering monitored acto-S1 complex reassociation in the absence, or presence of 1 and $5 \mu \mathrm{M}$ $\mathrm{V}_{10}$, i.e., 10 and $50 \mu \mathrm{M}$ total vanadium added as decavanadate (inset plot). The experiments were carried out at $25^{\circ} \mathrm{C}$ in $20 \mathrm{mM}$ Hepes (pH 7.0), $25 \mathrm{mM} \mathrm{KCl}$ and $2.5 \mathrm{mM} \mathrm{MgCl}_{2}$ with $0.9 \mu \mathrm{M}$ of $\mathrm{S} 1$ and $2 \mu \mathrm{M}$ actin.

dependent on the concentration of $\mathrm{V}_{10}$. The increase of the time after addition of ATP needed for the onset of the reassociation process in the presence of $\mathrm{V}_{10}$ correlated well with the extent of inhibition of the S1 ATPase activity by $\mathrm{V}_{10}$, thus indicating that is the time needed to attain a sufficiently low ATP level in the solution to allow for the reassociation process to occur. Remarkably, however, the kinetics of the reassociation between $\mathrm{S} 1$ and actin is notably slowed in the presence of $\mathrm{V}_{10}$ (inset of Figure 5C), suggesting the formation of nonproductive complexes induced by $\mathrm{V}_{10}$.

The formation of the complex between actin and S1 can also be monitored by fluorescence energy transfer $(48,51$, 52). To this end, we have labeled S1 with IAF (as the fluorescent donor) and F-actin with eosin iodoacetamide (eosin-F-actin). $\mathrm{V}_{10}$ produced only a small decrease of energy transfer between IAF-S1 and eosin-F-actin, from 20 to $15 \%$ in the absence and the presence of $5 \mu \mathrm{M} \mathrm{V}_{10}(50$ $\mu \mathrm{M}$ total vanadium) after correction for the effect of $\mathrm{V}_{10}$ on IAF-S1 fluorescence (results not shown). Using the overlap integral value (J) between $\mathrm{IAF}-\mathrm{S} 1$ and eosin-F-actin and donor (fluorescein in IAF-S1) quantum yield $\left(\mathrm{Q}_{\mathrm{D}}\right)$ which we have determined for our labeled samples $(J=5.52 \times$ $10^{-14} \mathrm{~cm}^{3} \mathrm{M}^{-1}$ and $\left.\mathrm{Q}_{\mathrm{D}}=0.35 \pm 0.05\right)$, we have obtained a $R_{0}$ value for this donor-acceptor pair of $3.9 \pm 0.1 \mathrm{~nm}$. Applying eq 1 of Materials and Methods, we have obtained a distance between donor (fluorescein) and acceptor (eosin) located in S1 and F-actin of $4.9 \pm 0.1$ and $5.2 \pm 0.1 \mathrm{~nm}$ in the absence and in the presence of $5 \mu \mathrm{M} \mathrm{V}_{10}(50 \mu \mathrm{M}$ total vanadium), respectively. Our distance estimation between donor and acceptor dyes in the F-actin/S1 complex agrees well with the values reported by others $(48,51,52)$, and the results confirm that $\mathrm{V}_{10}$ does not significantly dissociate the F-actin/S1 complex in the experimental conditions that produced a large inhibition of the actin-stimulated S1-ATPase activity.

\section{DISCUSSION}

The kinetic studies presented in this paper showed that $\mathrm{V}_{10}$ inhibits the actin-stimulated ATPase activity of myosin $\mathrm{S} 1$, with an $\mathrm{IC}_{50}$ in the micromolar range, that this inhibition is noncompetitive either with actin or with ATP, and suggested that it can be due to the interaction of $\mathrm{V}_{10}$ with one inhibitory binding site per myosin $\mathrm{S} 1$ with a $K_{\mathrm{i}}$ value of $0.27 \pm 0.05 \mu \mathrm{M}$ at $\mathrm{pH} 7.0$ in the conditions used for the kinetic assays. This $K_{\mathrm{i}}$ value is in the range of $K_{\mathrm{i}}$ values usually found for enzymes inhibited by $\mathrm{V}_{10}$ (53). The large effect of $\mathrm{KCl}$ on the dissociation constant of $\mathrm{V}_{10}$ from $\mathrm{S} 1$ indicates that electrostatic interactions plays a major role in $\mathrm{V}_{10}$ (a polyanion) binding to myosin. The presence of a binding site for polyvalent anions in the head of myosin has been well documented $(14,54-57)$, and it was proposed that they could account for the inhibition of the actomyosin ATPase activity by polyvalent anions (54). Although the surface electrostatic charge contour of S1 reveals the presence of a protein region positively charged from residues 627 to 646, containing five Lys (loop 2), which makes part of the actin-binding interface (50), it is very unlikely that the $\mathrm{V}_{10}$ polyanion high-affinity binding site we are probing at the present work is located at this protein region because $\mathrm{V}_{10}$ binding to $\mathrm{S} 1$ is not affected by actin.

In this paper, we have shown that S1 labeled at Cys-707 with IAEDANS or IAF monitor the presence of one $\mathrm{V}_{10}$ binding site per monomer, with a dissociation constant in the submicromolar range in the absence of nucleotides (ADP or ATP), $K_{\mathrm{d}}=0.16-0.26 \mu \mathrm{M}$ at $25 \mathrm{mM} \mathrm{KCl}$ concentration. These values of the dissociation constant of the $\mathrm{V}_{10} \cdot \mathrm{S} 1$ complex are close to the values for the inhibition constant $K_{\mathrm{i}}$ obtained from kinetic studies carried out with unlabeled S1 under the same experimental conditions, showing that 
labeling of $\mathrm{S} 1$ at Cys-707 produced only a minor distortion of the $\mathrm{V}_{10}$ binding site. In contrast, titration of S1(AEDANS, $\left.\mathrm{SH}_{2}\right)$ and of $\mathrm{S} 1\left(\mathrm{AF}, \mathrm{SH}_{2}\right)$ with metavanadate showed that orthovanadate has a much weaker affinity for S1, i.e., a $K_{\mathrm{d}}$ $>50 \mu \mathrm{M}$, and consistently orthovanadate was found to be only a weak competitor of decameric vanadate for binding to this site. It is also shown that binding of $\mathrm{V}_{10}$ species can be monitored as well from the quenching of the fluorescence of S1 labeled with IAEDANS and IAF at the Cys-697 $\left(\mathrm{SH}_{2}\right.$ group), located $1.8 \mathrm{~nm}$ from Cys-707 in the 3D-structure of S1 (50), yielding values for the dissociation constant which are similar to those obtained with S1 labeled with these dyes at Cys-707 ( $\mathrm{SH}_{1}$ group).

The extent of quenching produced by $\mathrm{V}_{10}$ on S1(AEDANS, $\mathrm{SH}_{2}$ ) (30\% at saturation) is much higher than the quenching produced at saturation upon binding of many ligands to S1(AEDANS, $\mathrm{SH}_{2}$ ) (23). Also, the quenching produced by $\mathrm{V}_{10}$ on $\mathrm{S} 1\left(\mathrm{SH}_{1}, \mathrm{AEDANS}\right)(35-40 \%$ at saturation) is about $15-$ $20 \%$ higher than that produced on $\mathrm{S} 1\left(\mathrm{SH}_{1}, \mathrm{AF}\right)(20-25 \%$ at saturation), although the labels were incorporated to the same Cys-697 in S1 (see Materials and Methods). The simplest way to account for this anomalous high quenching is that $\mathrm{V}_{10}$ binds to a site very close to the AEDANS covalently bound to $\mathrm{S} 1$, thereby producing a highly efficient static quenching (which implies that both sites are separated by at most $1.0 \mathrm{~nm}(58)$ ) or acting as a good acceptor for the fluorescence of AEDANS due to its absorption in the emission wavelength range of AEDANS (calculated value of the overlap integral $\left.J=0.223 \times 10^{-15} \mathrm{~cm}^{3} \mathrm{M}^{-1}\right)$. In this latter case, assuming that the excess quenching produced by $\mathrm{V}_{10}$ on $\mathrm{S} 1\left(\mathrm{SH}_{1}\right.$, AEDANS $)$ with respect to that measured for $\mathrm{S} 1\left(\mathrm{SH}_{1}, \mathrm{AF}\right)$ is due to energy transfer from IAEDANS to $\mathrm{V}_{10}$, with the overlap integral indicated above and the quantum yield obtained for AEDANS labeled $\mathrm{S} 1\left(Q_{\mathrm{D}}=0.18\right.$ \pm 0.03 , calculated as indicated in the Materials and Methods) we obtain an $R_{0}$ value of $1.39 \pm 0.04 \mathrm{~nm}$ for this donor/ acceptor energy transfer pair. Using eq 1 (see Materials and Methods), this will imply that the binding site for $\mathrm{V}_{10}$ is only at $1.2-1.3 \mathrm{~nm}$ distance from AEDANS covalently bound to Cys-697 in S1. The uncertainty caused by the assumption of random orientation between AEDANS and $V_{10}$ in this distance estimation is low because (i) the measured fluorescence anisotropy of the donor (AEDANS bound to S1) is 0.15 , which indicates a large rotational mobility of the donor (calculated rotational cone semiangle $\theta=41.5^{\circ}$ (see 38)); and (ii) the quasi-spherical geometry of the acceptor $\mathrm{V}_{10}$.

The flexible loop between Cys-707 and Cys-697 is thought to act as an energy transduction element through which intersite communication between ATP and actin binding sites is transmitted. In fact, this region is known to change its conformation along the ATPase kinetic pathway $(21,24,25)$. Therefore, conformational changes leading to transient intermediate states during the catalytic cycle could alter the affinity of myosin $\mathrm{S} 1$ for $\mathrm{V}_{10}$. $\mathrm{ADP} \cdot \mathrm{V}_{1}$ and $\mathrm{ADP} \cdot \mathrm{AlF}_{4}$ have been shown to shift $\mathrm{S} 1$ to a state close to the $\mathrm{M}^{* *} \cdot \mathrm{ADP} \cdot \mathrm{P}_{\mathrm{i}}$ intermediate state generated during myosin ATPase activity $(22,59,60)$. Noteworthy, the dissociation constant of S1 for $\mathrm{V}_{10}$ increased approximately 2- and 3-fold in the presence of $\mathrm{ADP} \cdot \mathrm{V}_{1}$ and $\mathrm{ADP} \cdot \mathrm{AlF}_{4}$, respectively, suggesting that $\mathrm{V}_{10}$ has 2-3-fold lower affinity for the conformational state $\mathrm{M}^{* *}$. ADP.Pi than for S1 conformational state in absence of nucleotide. Different affinities for $\mathrm{V}_{10}$ of different conformational states of myosin $\mathrm{S} 1$ should be expected to produce an altered distribution of conformational states during steadystate $\mathrm{S} 1$ catalytic activity in the presence of $\mathrm{V}_{10}$. In the present work, it is demonstrated that $\mathrm{V}_{10}$ induced a small change in the light scattering of the actin-S1 complex and a decrease of the fluorescence energy transfer between IAFS1, with the donor dye covalently attached to Cys-707 of myosin, and eosin-F-actin, with the acceptor dye covalently attached to Cys-374 of actin. The decrease of fluorescence energy transfer produced by $\mathrm{V}_{10}$ in the IAF-S1/eosin-Factin complex can be accounted for an increase of $3.0 \pm$ $1.2 \AA$ of the distance between donor and acceptor dyes or a change in the relative orientation between donor and acceptor of about $25^{\circ}$. Such a change in distance falls within the range of conformational-induced changes in distance between one dye covalently bound to selected Cys or Lys amino acids in the myosin $\mathrm{S} 1$ and a second dye attached to F-actin (48, 52 ), and also is in good agreement with the reported dynamic structural fluctuation range of the myosin S1 between Cys707 and Cys-697 (61, 62).

In presence of saturating concentrations of $\mathrm{AP}_{5} \mathrm{~A}$ the association constant for $\mathrm{V}_{10}$ binding to $\mathrm{S} 1$ is approximately 36-fold lower than in absence of $\mathrm{AP}_{5} \mathrm{~A}$. Furthermore, at saturation $\mathrm{V}_{10}$ also decreased almost 4-fold the association constant for $\mathrm{AP}_{5} \mathrm{~A}$ binding to $\mathrm{S} 1$. Therefore, $\mathrm{V}_{10}$ and $\mathrm{AP}_{5} \mathrm{~A}$ compete for binding to $\mathrm{S} 1$, suggesting that their binding sites partially overlap or that they are very close in the $3 \mathrm{D}$ protein structure. Computer molecular docking of $\mathrm{AP}_{5} \mathrm{~A}$ to $\mathrm{S} 1$ has shown that this $\gamma$-phosphate modified nucleotide analogue binds to $\mathrm{S} 1$, extending from the nucleotide binding site through the phosphate tube leading to the $50-\mathrm{K}$ cleft ( 16 , 49 ), but through a prior opening of the phosphate tube. This tube structure that connects the nucleotide crevice of the catalytic center and the back door in the 50-K cleft switches between open and closed states during the catalytic cycle $(16,49)$. Release of myosin from actin is caused by opening the cleft between the lower and upper domains of the 50$\mathrm{kDa}$ segment when the $\gamma$-phosphate from ATP binds in the active site pocket (50). The $\gamma$-phosphate of ATP lies adjacent to Ser-180 and Ser-243, two residues known to be photomodified by vanadate upon UV irradiation (15). Ser-180 is located on the 178-185 sequence which forms the consensus ATP binding site of myosin and is homologous to the polyphosphate binding site of a number of nucleotide binding enzymes (63). Recently, Pezza et al. (64) have shown that the Walker A motif of ABC ATPases is a highly adapted anion-binding domain that can bind $\mathrm{V}_{10}$ with a dissociation constant in the micromolar range and produce noncompetitive inhibition. According to these authors, once the complex decavanadate $-\mathrm{ADP}-\mathrm{Mg}-$ protein is established, the ATP/ ADP exchange can be blocked, resulting in noncompetitive inhibition with respect to ATP. In the present work, the putative binding of $\mathrm{V}_{10}$ to the P-loop in S1 3D structure can account for the results reported, briefly: (i) noncompetitive inhibition with actin and ATP of the actin-stimulated S1ATPase activity and slower reassociation between S1 and actin after ATP hydrolysis; (ii) large alteration of the fluorescence of AEDANS and AF covalently bound to Cys707 and Cys-697 located near the P-loop in the 3D structure of $\mathrm{S} 1$; (iii) competition with $\mathrm{AP}_{5} \mathrm{~A}$ for binding to $\mathrm{S} 1$; and (iv) a conformational shift of $\mathrm{S} 1$, as this P-loop orientation 
changes during the conformational changes taking place in the catalytic cycle of ATP hydrolysis (49).

In summary, the results are consistent with binding of $\mathrm{V}_{10}$ to the Walker A motif of ABC ATPases, which in S1 corresponds to conserved regions of the P-loop that form part of the phosphate tube. This $\mathrm{V}_{10}$ high-affinity binding site produces noncompetitive inhibition of the actinstimulated S1-ATPase activity, without causing dissociation of the acto-S1 complex. Moreover, the affinity of S1 for $\mathrm{V}_{10}$ is modulated by the conformational changes that takes place in S1 during the catalytic cycle, as indicated by the 2-3-fold increase of the dissociation constant produced in the presence of $\mathrm{ADP} \cdot \mathrm{V}_{1}$ and $\mathrm{ADP} \cdot \mathrm{AlF}_{4}$, which induce a conformational state close to the $\mathrm{M}^{* *} \cdot \mathrm{ADP} \cdot \mathrm{P}_{\mathrm{i}}$ intermediate state generated during myosin ATPase activity. Therefore, the $\mathrm{V}_{10}$ species can be a useful tool to gain a deeper knowledge of the "back door" modulation of the actinstimulated myosin ATPase activity and its relevance to actomyosin interactions.

\section{REFERENCES}

1. Chasteen, N. D. (1983) The biochemistry of vanadium. Struct. Bonding 53, 105-138.

2. Petterson, L., Andersson, I., and Hedman, B. (1985) Multicomponent polyanions. Chem. Scr. 25, 309-317.

3. Crans, D. C., Rithner, C. D., and Theisen, L. A. (1990) Timeresolved ${ }^{51} \mathrm{~V}$ 2-D NMR for studies of kinetic exchange between vanadate oligomers. J. Am. Chem. Soc. 112, 2901-2908.

4. Farahbakhsh, M., Kögerler, P., Schmidt, H., and Rehder, D. (1998) Wrapping oxometalates with macrocyclic ligands: the decavanadate-cryptand system. Inorg. Chem. Commun. 1, 111-114.

5. Aureliano, M., Joaquim, N., Sousa, A., Martins, H., Coucelo, J. M. (2002) Oxidative stress in toadfish (Halobatrachus didactylus) cardiac muscle: Acute exposure to vanadate oligomers. J. Inorg. Biochem. 90, 159-165.

6. Soares, S. S., Aureliano, M., Joaquim, N., Coucelo, J. M. (2003) Cadmium and vanadate oligomers effects on metahemoglobin reductase activity from Lusitanian toadfish: in vivo and in vitro studies. J. Inorg. Biochem. 94, 285-290.

7. Stankiewicz, P. J., Tracey, A. S., and Crans, D. C. (1995) Inhibition of phosphate-metabolizing enzymes by oxovanadium $(\mathrm{V})$ complexes in Metal ions in Biological Systems: Vanadium and its Role in Life (Sigel H., Sigel A., Ed.), pp 287-324, Marcel Dekker, New York.

8. Toyoshima, Y. Y., Kron, S. J., McNally, E. M., Niebling, K. R., Toyoshima, C., and Spudich, J. A. (1987) Myosin subfragment-1 is sufficient to move actin filaments in vitro. Nature $328,536-$ 539.

9. Lymn, R. W., and Taylor, E. W. (1971) Mechanism of adenosine triphosphate hydrolysis by actomyosin. Biochemistry 10, 46174624.

10. Goodno, C. C. (1979) Inhibition of myosin ATPase by vanadate ion. Proc. Natl. Acad. Sci. U.S.A. 76, 2620-2624.

11. Goodno, C. C. (1982) Myosin active-site trapping with vanadate ion. Methods Enzymol. 85, 116-123.

12. Goodno, C. C., and Taylor, E. W. (1982) Inhibition of actomyosin ATPase by vanadate. Proc. Natl. Acad. Sci. U.S.A. 79, 21-25.

13. Smith, S. J., and Eisenberg, E. (1990) A comparison of the effect of vanadate on the binding of myosin-subfragment-1 - ADP to actin and on actomyosin subfragment 1 ATPase activity. Eur. J. Biochem. 193, 69-73.

14. Ringel, I., Peyser, Y. M., and Muhlrad, A. (1990) ${ }^{51}$ V NMR study of vanadate binding to myosin and its subfragment 1. Biochemistry 29, 9091-9096.

15. Cremo, C. R., Long, G. T., and Grammer, J. C. (1990) Photocleavage of myosin subfragment 1 by vanadate. Biochemistry 29 , 7982-7990.

16. Yount, R. G., Lawson, D., and Rayment, I. (1995) Is myosin a "back door" enzyme? Biophys. J. 68, 44s-49s.

17. Aureliano, M. (2000) Vanadate oligomer interactions with myosin. J. Inorg. Biochem. 80, 141-143.
18. Tiago, T., Aureliano, M., and Gutiérrez-Merino, C. (2002) Quenching of myosin intrinsic fluorescence unravels the existence of a high affinity binding site for decavanadate. J. Fluoresc. 12, 87-90.

19. Howarth, O. W., and Jarold, M. (1978) Protonation of the decavanadate (6-) ion: a vanadium-51 nuclear magnetic resonance study. J. Chem. Soc., Dalton 503-506.

20. Cheung, H. C., Gonsoulin, F., and Garland, F. (1983) Fluorescence energy transfer studies on the proximity of the two essential thiols of myosin subfragment-1. J. Biol. Chem. 258, 5775-5786.

21. Aguirre, R., Gonsoulin, F., and Cheung, H. C. (1986) Interaction of fluorescently labeled myosin subfragment-1 with nucleotides and actin. Biochemistry 25, 6827-6835.

22. Werber, M. M., Peyser, M., and Muhlrad, A. (1992) Characterization of stable beryllium fluoride, aluminum fluoride, and vanadate containing myosin subfragment-1 nucleotide complexes. Biochemistry 31, 7190-7197.

23. Phan, B. C., Peyser, Y. M., Reisler, E., and Muhlrad, A. (1997) Effect of complexes of ADP and phosphate analogues on the conformation of the Cys707-Cys697 region of myosin subfragment 1. Eur. J. Biochem. 243, 636-642.

24. Reisler, E. (1982) Sulfhydryl modification and labeling of myosin. Methods Enzymol. 85, 84-93.

25. Maruta, S., Aihara, T., Uyehara, Y., Homma, K., Sugimoto, Y., and Wakabayashi, K. (2000) Solution Structure of myosin-ADP$\mathrm{MgFn}$ ternary complex by fluorescent probes and small-angle synchroton X-ray scattering. J. Biochem. 128, 687-694.

26. Pires, E. M. V., Perry, S. V., and Thomas, M. A. W. (1974) Myosin light-chain kinase, a new enzyme from striated muscle. FEBS Lett. 41, 292-296.

27. Margossian, S. S., and Lowey, S. (1982) Preparation of myosin and its subfragments from rabbit skeletal muscle. Methods Enzymol. 85, 55-72.

28. Pardee, J. D., and Spudich, J. A. (1982) Purification of muscle actin. Methods Enzymol. 85, 164-181.

29. Aureliano, M., and Madeira, V. M. C. (1994) Interactions of vanadate oligomers with sarcoplasmic reticulum $\mathrm{Ca}^{2+}$-ATPase. Biochim. Biophys. Acta 1221, 259-271.

30. Aureliano, M., and Madeira, V. M. C. (1998) Energy transduction mechanisms as affected by vanadium(V) species: $\mathrm{Ca}^{2+}$-pumping in sarcoplasmic reticulum. Adv. Environ. Sci. 30, 333-357.

31. Crans, D. C. (1994) Aqueous chemistry of labile oxovanadates: relevance to biological studies. Comments Inorg. Chem. 16, 1-33.

32. Crans, D. C. (1994) Enzyme interactions with labile oxovanadates and other polyoxometalates. Comments Inorg. Chem. 16, 35-76.

33. Cuenda, A., Henao, F., and Gutiérrez-Merino, C. (1990) Distances between functional sites of the $\mathrm{Ca}^{2+}$-ATPase from sarcoplasmic reticulum using $\mathrm{Co}^{2+}$ as a spectroscopic ruler. Eur. J. Biochem. 194, 663-670.

34. Bradford, M. M. (1976) A rapid and sensitive method for the quantification of microgram quantities of protein utilizing the principle of protein-dye binding. Anal. Biochem. 72, 248-254.

35. Fiske, C. H., and Subbarow, Y. (1925) The colorimetric determination of phosphorus. J. Biol. Chem. 66, 375-400.

36. Titus, M. A., Ashiba, G., and Szent-György, A. G. (1989) SH-1 modification of rabbit myosin interferes with calcium regulation. J. Muscle Res. Cell Motil. 10, 25-33.

37. Lakowicz, J. R. (1983) in Principles of Fluorescence Spectroscopy, pp 44-45, Plenum Press, New York.

38. Weber, G. (1966) in Fluorescence and Phosphorescence Analysis (Hercules, D. M, Ed.), pp 217-240, John Wiley and Sons, New York.

39. Stryer, L. (1978) Fluorescence energy transfer as a spectroscopic ruler. Annu. Rev. Biochem. 47, 819-846.

40. Gutiérrez-Merino, C., Munkonge, F., Mata, A. M., East, J. M., Levinson, B. L., Napier, R. M., and Lee, A. G. (1987) The position of the ATP binding site on the $\left(\mathrm{Ca}^{2+}, \mathrm{Mg}^{2+}\right)$-ATPase. Biochim. Biophys. Acta 897, 207-216.

41. Förster, T. (1965) in Modern Quantum Chemistry (Sinanoglu, O., Ed.), Academic Press, New York.

42. Centeno, F., and Gutiérrez-Merino, C. (1992) Location of functional centers in the microsomal cytochrome P450 system. Biochemistry 31, 8473-8481.

43. Bauer, C. B., Kuhlman, P. A., Bagshaw, C. R., and Rayment, I. (1997) X-ray Crystal Structure and Solution Fluorescence Characterization of $\mathrm{Mg} \cdot 2^{\prime}\left(3^{\prime}\right)-O$ - $(N$-Methylanthraniloyl) Nucleotides Bound to the Dictyostelium discoideum Myosin Motor Domain. J. Mol. Biol. 274, 394-407. 
44. Cooper, J. A., and Pollard, T. D. (1982) Methods to measure actin polymerisation. Methods Enzymol. 85, 182-211.

45. Balint, M., Wolf, I., Tarcsafalvi, A., Gergely, J., and Sreter, F. A. (1978) Location of SH-1 and SH-2 in the heavy chain segment of heavy meromyosin. Arch. Biochem. Biophys. 190, 793-799.

46. Eisenberg, E., and Hill, T. L. (1985) Muscle contraction and free energy transduction in biological systems. Science 227, 999-1006.

47. Lin, S. H., and Cheung, H. C. (1991) Two-state equilibria of myosin subfragment 1 and its complexes with ADP and actin. Biochemistry 30, 4317-4322.

48. Xing, J., and Cheung, H. C. (1995) Internal movement in myosin subfragment 1 detected by fluorescence resonance energy transfer. Biochemistry 34, 6475-6487.

49. Pate, E., Naber, N., Matuska, M., Franks-Skiba, K., and Cooke, R. (1997) Opening of the myosin nucleotide triphosphate binding domain during the ATPase cycle. Biochemistry 36, 12155-12166.

50. Rayment, I., Rypniewski, W. R., Schmidt-Bäse, K., Smith, R., Tomchick, D. R., Benning, M. M., Winkelmann, D. A., Wesenberg, G., and Holden, H. M. (1993) Three-dimensional structure of myosin subfragment-1: a molecular motor. Science 261, 5058.

51. Trayer, H. R., and Trayer, I. P. (1983) Fluorescence energy transfer between the myosin subfragment-1 isoenzymes and F-actin in the absence and presence of nucleotides. Eur. J. Biochem. 135, 4759.

52. Smyczynski, C., and Kasprzak, A. A. (1997) Effect of nucleotides and actin on the orientation of the light chain-binding domain in myosin subfragment 1 . Biochemistry 36, 13201-13207.

53. Messmore, J. M., and Raines, R. T. (2000) Decavanadate inhibits catalysis by ribonuclease A. Arch. Biochem. Biophys. 381, 2530.

54. Labbé, J. P., Bertrand, R., Audemard, E., Kassab, R., Walzthony, D., and Wallimann, T. (1984) The interaction of skeletal myosin subfragment 1 with the polyanion, heparin. Eur. J. Biochem. 143, 315-322.

55. Chaussepied, P., Mornet, D., and Kassab, R. (1986) Identification of polyphosphate recognition sites communicating with actin sites on the skeletal myosin subfragment 1 heavy chain. Biochemistry $25,6426-6432$.
56. Muhlrad, A. (1991) The isolated $21 \mathrm{kDa}$ N-terminal fragment of myosin binds to actin in an ATP and ionic strength-dependent manner. Biochim. Biophys. Acta 1077, 308-315.

57. Sanz, S., Gil, M. J., Lopez-Zabalza, M. J., Lopez-Moratalla, N., and Santiago, E. (1992) Conformational changes of S-1 related to its dissociation from actin. Rev. Esp. Fisiol. 48, 51-57.

58. London, E., and Feigenson, G. W. (1981) Fluorescence Quenching in Model membranes. 1. Characterization of Quenching Caused by a Spin-Labeled Phospholipid. Biochemistry 20, 1932-1938.

59. Peyser, Y. M., Ben-Hur, M., Werber, M. M., and Muhlrad, A (1996) Effect of divalent cations on the formation and stability of myosin subfragment 1-ADP-phosphate analog complexes. Biochemistry 35, 4409-4416.

60. Smith, R., and Rayment, I. (1996) X-ray structure of the magnesium(II) ADP $\cdot$ vanadate complex of the Dictyostelium discoideum myosin motor domain to $1.9 \AA$ resolution. Biochemistry $35,5404-5417$.

61. Cheung, H. C., Garland, F., and Gonsoulin, F. (1985) An investigation of the SH1-SH2 and SH1-ATPase distances in myosin subfragment-1 by resonance energy transfer using nanosecond fluorimetry. Biochim. Biophys. Acta 832, 52-62.

62. Cheung, H. C., Gryczynski, I., Malak, H., Wiczk, W., Johnson, M. L., and Lakowicz, J. R. (1991) Conformational flexibility of the Cys 697-Cys 707 segment of myosin subfragment-1. Distance distributions by frequency-domain fluorometry. Biophys. Chem. $40,1-17$

63. Walker, J. E., Saraste, M., Runswick, M. J., and Gay, N. J. (1982) Distantly related sequences in the alpha- and beta-subunits of ATP synthase, myosin, kinases and other ATP-requiring enzymes and a common nucleotide binding fold. EMBO J. 1, 945-951.

64. Pezza, R. J., Villarreal, M. A., Montich, G. G., and Argaraña, C. E. (2002) Vanadate inhibits the ATPase activity and DNA binding capability of bacterial MutS. A structural model for the vanadateMutS interaction at the Walker A motif. Nucleic Acids Res. 30 $4700-4708$.

BI049910+ 